\title{
THE INDEX OF REFRACTION OF SOME SODA-LIMESIL- ICA GLASSES AS A FUNCTION OF THE COMPOSITION
}

\author{
By C. A. Faick and A. N. Finn
}

\section{ABSTRACT}

Twenty-one soda-silica and twenty-one soda-lime-silica glasses were made in platinum and the index of refraction and chemical composition of each glass were determined. From the data obtained equations were derived and a diagram was prepared showing the relations between index of refraction and composition of these glasses.

The diagram makes it possible to predict with considerable accuracy (1) the index of refraction of any glass, in the range of compositions considered, from its composition and (2) the compositions of the various glasses which have the same index of refraction.

Some evidence is presented indicating that index of refraction of the soda-silica glasses may be a simple function of certain soda-silica compounds which may be present in glass.

\section{CONTENTS}

I. Introduction Page

II. Outline of the work

III. Making the glass

IV. Measurement of index of refraction 994

V. Data obtained and results _....... 996

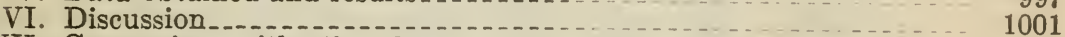

VII. Comparison with other data ........ 1002

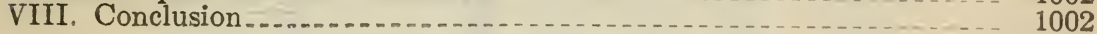

\section{INTRODUCTION}

Although the relation between index of refraction and chemical composition of glass has been given considerable attention in the past, most of the work has been done on glass whose composition and heat treatment are not definitely known. Many of the previous investigators based their work on compositions computed from the batch, disregarding material dissolved from the pot. Others analyzed the glasses and almost invariably found small amounts of oxides whose presence was unintended and complicated any adequate analysis of the data. Tillotson ${ }^{1}$ and Peddle ${ }^{2}$ for example, based their work on batch compositions. Turner, ${ }^{3}$ however, analyzed his glasses; but they contained varying amounts of $\mathrm{Al}_{2} \mathrm{O}_{3}, \mathrm{Fe}_{2} \mathrm{O}_{3}$, and $\mathrm{MgO}$, which confuse the issue when studying a 2 or 3 component system. Consequently, the results obtained by these investigators are not all that might be desired.

A diagram by Morey and Merwin showing the relations between composition and index of refraction of soda-lime-silica glasses has been published, ${ }^{4}$ but the data on which these relations are based have not yet been presented.

1 J. Ind. and Eng. Chem., 3, p. 897; 1911; 4, p. 246; 1912.

2 J. Soc. G1. Tech., 4, 1920; 5,$1921 ; 6,1922 ; 7,1923$.

s J. Soc. Gl. Tech., 4, 1920; $\mathbf{5}, 1921 ; 6,1922 ; \boldsymbol{7}, 1923$.

- Int. Crit. Tables, ?, p. 102. 
Finn and Thomson, ${ }^{5}$ analyzing such data from the literature as were available for the purpose, obtained a series of equations for expressing the relation between index of refraction and composition. Since their analysis indicated that more satisfactory results might be obtained by further careful experimental study of the subject, it was iecided that this work should be undertaken.

\section{OUTLINE OF THE WORK}

In order properly to investigate the variation in index of refraction with changes in chemical composition, it was considered desirable to study first the 2-component system, soda-silica, and then to extend the work to the 3-component system, soda-lime-silica. The composition of the glasses varied from approximately 50 per cent each of soda and silica to 14 per cent soda-86 per cent silica in the 2-component system; in the 3-component system lime varied from approximately 3 to 15 per cent.

To obtain glasses containing only the two or three constituents under consideration would necessitate the reduction to a minimum of all impurities in the batch material and the prevention of contamination during melting. Consequently, only the best batch materials available were used. The soda and lime were introduced as sodium ('arbonate and calcium carbonate of reagent quality. The silica was prepared by pulverizing portions of a large, colorless, transparent quartz crystal. $^{6}$ The glasses were melted in a $25 \mathrm{ml}$ platinum crucible to prevent contamination during melting, and were annealed at upproximately their highest annealing temperature. Although the glasses were made from pure materials and melted in platinum, their compositions were subsequently determined by careful chemical unalyses.

\section{MAKING THE GLASS}

To produce the desired glasses a special platinum resistance furnace was constructed. The heating unit consisted of approximately 40 turns of $0.8 \mathrm{~mm} 80$ per cent platinum- 20 per cent rhodium wire wound on an alundum core of the following dimensions: Bore, 2 inches; wall, $3 / 8$ inch; length, 12 inches. It was surrounded by about 1 inch of electrically sintered magnesia, the rest of the insulation being dintomaceous silica. The furnace was supported about 16 inches above the table to facilitate manipulations incident to melting the glass. The platinum crucible was handled by placing it in the end of a long refractory tube whose inside diameter was slightly less than the diameter of the crucible at the top. This "holder" when in place reached about halfway into the furnace and extended about 8 inches below it. It was so supported by a sliding-clamp arrangement that it could be quickly raised or lowered and swung clear of the furnace for purposes of filling and stirring. (See fig. 1.) A platinum and platium-rhodium thermocouple for measuring temperature was placed inside the cruciblc-supporting tube, with its junction nearly touching

J. Am. C'er. Soc., 8; No. 8, August, 1925.

(1) The signiflement impurities in the batch materials were found to be as follows: The sodium carbonate (1) ntulumd 0.002 per cont $\mathrm{Sic})_{2}, 0 .\left(003\right.$ per cent $\mathrm{R}_{2} \mathrm{O}_{3}, 0.003$ per cent $\mathrm{MgO}$, and 0.013 per cent $\mathrm{K}_{2} \mathrm{O}$; the calcium ar $1 \mathrm{H}_{2}=\mathrm{O}_{6}$ ). 
B. S. Journal of Research, RP320

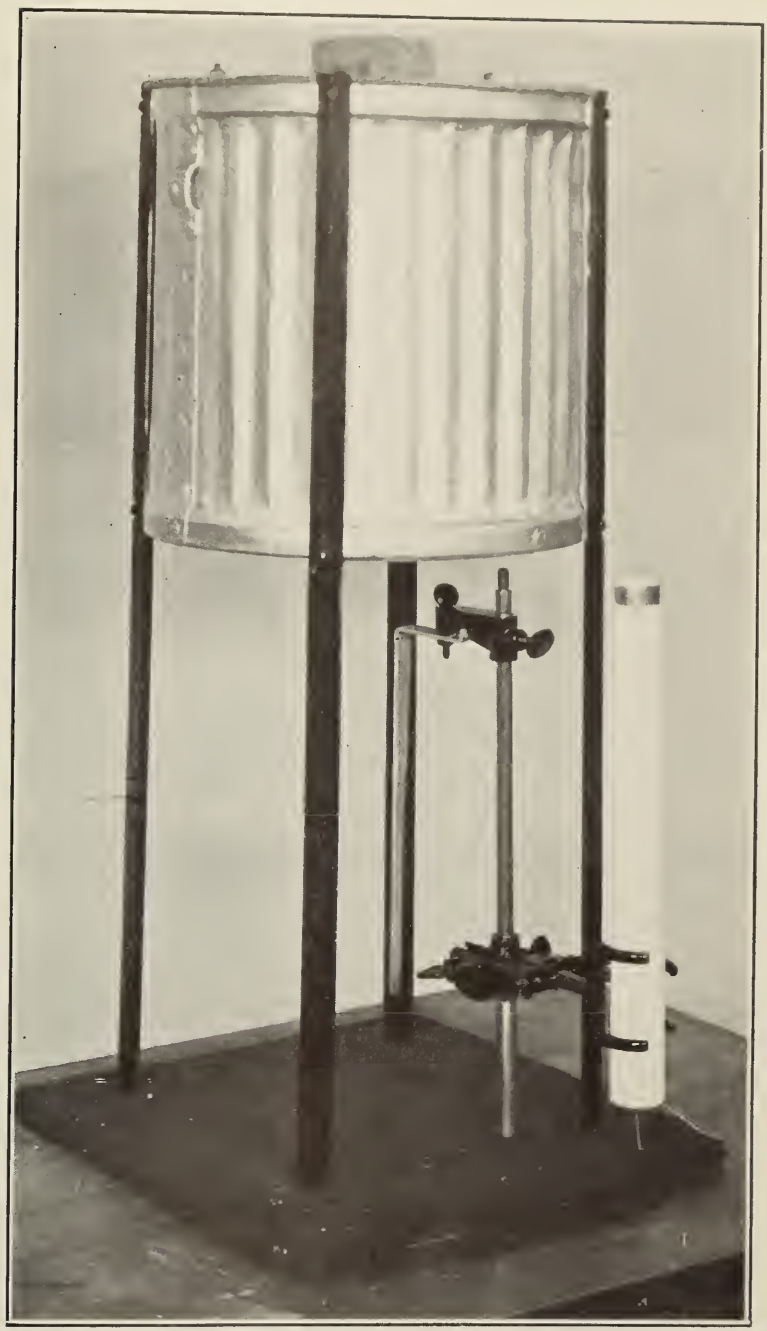

Figure 1.-Melting furnace, showing the platinum crucible (in the refractory holder) in position for filling or stirring 
the crucible and its terminals extending out of the lower end. Extension leads connected the thermocouple to a potentiometer.

The filling was done at frequent intervals by lowering the crucible, swinging it clear of the furnace and adding small amounts of batch. Stirring was done with a platinum rod, the crucible being in the same position as for filling. After the glass was free from seeds and carefully stirred to eliminate striæ, it was poured from the crucible into an iron mold. This was done by removing the tube from its clamp and inverting it, thus obviating the necessity of handling the hot platinum crucible. The glass while still hot was transferred from tho mold to a muffle furnace for annealing; the furnace being at a selected annealing temperature at the time of transfer. (See Table 1.)

The size of the samples of glass obtained was approximately 50 by 30 by $5 \mathrm{~mm}$.

TABLE 1.-Compositions, observed and calculated indices of refraction and dif-

ferences between observed and calculated values of some soda-silica and sodalime-silica glasses

\begin{tabular}{|c|c|c|c|c|c|c|c|c|c|}
\hline \multirow{2}{*}{$\begin{array}{c}\text { Glass } \\
\text { No. }\end{array}$} & \multicolumn{3}{|c|}{ Composition } & \multirow{2}{*}{$-\begin{array}{c}\text { Observed } \\
\text { index }\end{array}$} & \multicolumn{4}{|c|}{ Computed index and differences } & \multirow{2}{*}{$\begin{array}{l}\text { Anneal- } \\
\text { ing } \\
\text { temper- } \\
\text { ature }\end{array}$} \\
\hline & $\mathrm{SiO}_{2}$ & $\mathrm{Na}_{2} \mathrm{O}$ & $\mathrm{CaO}$ & & A1 & $\mathrm{A} 2$ & B1 & $\mathrm{B} 2$ & \\
\hline $\begin{array}{l}3 \\
4 \\
5\end{array}$ & $\begin{array}{r}\text { Per cent } \\
50.04 \\
51.26 \\
52.15 \\
54.14 \\
57.45\end{array}$ & $\begin{array}{r}\text { Per cent } \\
49.96 \\
48.74 \\
47.85 \\
45.86 \\
42.55\end{array}$ & Per cent & $\begin{array}{l}1.5163 \\
1.5146 \\
1.5150 \\
1.5137 \\
1.5112\end{array}$ & $\begin{array}{l}1.5159 \\
1.5152 \\
1.5148 \\
1.5137 \\
1.5116\end{array}$ & $\begin{array}{r}-0.0004 \\
+.0006 \\
-.0002 \\
+.0000 \\
+.0004\end{array}$ & $\begin{array}{l}1.5158 \\
1.5153 \\
1.5150 \\
1.5136 \\
1.5115\end{array}$ & $\begin{array}{r}-0.0005 \\
+.0007 \\
.0000 \\
-.0001 \\
+.0003\end{array}$ & $\begin{array}{l}{ }^{\circ} \mathrm{C} . \\
415 \\
420 \\
420 \\
420 \\
430\end{array}$ \\
\hline $\begin{array}{l}6- \\
7- \\
8- \\
9-\end{array}$ & \begin{tabular}{l|}
59.97 \\
62.86 \\
63.06 \\
65.30 \\
65.32
\end{tabular} & $\begin{array}{l}40.03 \\
37.14 \\
36.94 \\
34.70 \\
34.68\end{array}$ & & $\begin{array}{l}1.5099 \\
1.5076 \\
1.5075 \\
1.5055 \\
1.5055\end{array}$ & $\begin{array}{l}1.5101 \\
1.5076 \\
1.5077 \\
1.5056 \\
1.5056\end{array}$ & $\begin{array}{r}+.0002 \\
.0000 \\
+.0002 \\
+.0001 \\
+.0001\end{array}$ & $\begin{array}{l}1.5097 \\
1.5075 \\
1.5073 \\
1.5055 \\
1.5055\end{array}$ & $\begin{array}{r}-.0602 \\
-.0001 \\
-.0002 \\
.0000 \\
.0000\end{array}$ & $\begin{array}{r}430 \\
.440 \\
440 \\
450 \\
480\end{array}$ \\
\hline $\begin{array}{l}3 . \\
4 \\
5\end{array}$ & $\begin{array}{l}67.14 \\
69.65 \\
70.21 \\
70.44 \\
72.15\end{array}$ & $\begin{array}{l}32.86 \\
30.35 \\
29.79 \\
29.56 \\
27.85\end{array}$ & & $\begin{array}{l}1.5042 \\
1.5021 \\
1.5014 \\
1.5015 \\
1.4993\end{array}$ & $\begin{array}{l}1.5039 \\
1.5015 \\
1.5009 \\
1.5017 \\
1.4992\end{array}$ & $\begin{array}{r}-.0003 \\
-.0006 \\
-.0005 \\
+.0002 \\
-.0001\end{array}$ & $\begin{array}{l}1.5041 \\
1.5022 \\
1.5017 \\
1.5015 \\
1.5002\end{array}$ & $\begin{array}{r}-.0001 \\
+.0001 \\
+.0003 \\
.0000 \\
+.0009\end{array}$ & $\begin{array}{l}500 \\
515 \\
525 \\
525 \\
525\end{array}$ \\
\hline 6 & $\begin{array}{l}75.29 \\
77.85 \\
78.61 \\
79.73 \\
83.00\end{array}$ & $\begin{array}{l}24.71 \\
22.15 \\
21.39 \\
20.27 \\
17.00\end{array}$ & & $\begin{array}{l}1.4965 \\
1.4925 \\
1.4912 \\
1.4898 \\
1.4851\end{array}$ & $\begin{array}{l}1.4955 \\
1.4923 \\
1.4915 \\
1.4900 \\
1.4857\end{array}$ & $\begin{array}{r}-.0010 \\
-.0002 \\
+.0003 \\
+.0002 \\
+.0006\end{array}$ & $\begin{array}{l}1.4967 \\
1.4926 \\
1.4914 \\
1.4898 \\
1.4846\end{array}$ & $\begin{array}{r}+.0002 \\
+.0001 \\
+.0002 \\
.0000 \\
-.0005\end{array}$ & $\begin{array}{l}560 \\
575 \\
575 \\
575 \\
600\end{array}$ \\
\hline 5 & $\begin{array}{l}86.41 \\
52.65 \\
51.37 \\
56.20 \\
56.76\end{array}$ & $\begin{array}{l}13.59 \\
43.05 \\
32.85 \\
34.00 \\
37.48\end{array}$ & $\begin{array}{r}4.30 \\
12.78 \\
9.80 \\
5.76\end{array}$ & $\begin{array}{l}1.4790 \\
1.5234 \\
1.5391 \\
1.5320 \\
1.5238\end{array}$ & $\begin{array}{l}1.4809 \\
1.5233 \\
1.5393 \\
1.5322 \\
1.5237\end{array}$ & $\begin{array}{l}+.0019 \\
+.0001 \\
+.0002 \\
+.0002 \\
-.0001\end{array}$ & $\begin{array}{l}1.4794 \\
1.5233 \\
1.5394 \\
1.5322 \\
1.5236\end{array}$ & $\begin{array}{r}+.0004 \\
-.0001 \\
+.0003 \\
+.0002 \\
-.0002\end{array}$ & $\begin{array}{l}600 \\
450 \\
530 \\
480 \\
470\end{array}$ \\
\hline $\begin{array}{l}28 \\
29 \\
30\end{array}$ & $\begin{array}{l}58.41 \\
60.32 \\
63.34 \\
64.14 \\
64.70\end{array}$ & $\begin{array}{l}38.54 \\
24.50 \\
24.39 \\
21.22 \\
26.84\end{array}$ & $\begin{array}{r}3.05 \\
15.18 \\
12.27 \\
14.64 \\
8.46\end{array}$ & $\begin{array}{l}1.5170 \\
1.5395 \\
1.5320 \\
1.5360 \\
1.5232\end{array}$ & $\begin{array}{l}1.5172 \\
1.5404 \\
1.5321 \\
1.5361 \\
1.5231\end{array}$ & $\begin{array}{r}+.0002 \\
+.0009 \\
+.0001 \\
+.0001 \\
-.0001\end{array}$ & $\begin{array}{l}1.5170 \\
1.5403 \\
1.5321 \\
1.5363 \\
1.5233\end{array}$ & $\begin{array}{r}.0000 \\
+.0008 \\
+.0001 \\
+.0003 \\
+.0001\end{array}$ & $\begin{array}{l}480 \\
530 \\
525 \\
565 \\
525\end{array}$ \\
\hline $\begin{array}{l}31 . \\
32 . \\
33 . \\
34 .\end{array}$ & $\begin{array}{l}65.71 \\
66.47 \\
67.30 \\
67.98\end{array}$ & $\begin{array}{l}28.79 \\
21.74 \\
29.43 \\
22.50\end{array}$ & $\begin{array}{r}5.50 \\
11.79 \\
3.27 \\
9.52\end{array}$ & $\begin{array}{l}1.5167 \\
1.5288 \\
1.5110 \\
1.5230\end{array}$ & $\begin{array}{l}1.5163 \\
1.5283 \\
1.5103 \\
1.5223\end{array}$ & $\begin{array}{l}-.0004 \\
-.0005 \\
-.0007 \\
-.0007\end{array}$ & $\begin{array}{l}1.5165 \\
1.5256 \\
1.5107 \\
1.5228\end{array}$ & $\begin{array}{l}-.0002 \\
-.0002 \\
-.0003 \\
-.0002\end{array}$ & $\begin{array}{l}520 \\
565 \\
520 \\
565\end{array}$ \\
\hline $\begin{array}{l}35 \\
36 \\
37 \\
38\end{array}$ & $\begin{array}{l}70.50 \\
72.08 \\
72.61 \\
74.09\end{array}$ & $\begin{array}{l}23.00 \\
14.21 \\
24.24 \\
15.23\end{array}$ & $\begin{array}{r}6.50 \\
13.71 \\
3.15 \\
10.68\end{array}$ & $\begin{array}{l}1.5145 \\
1.5265 \\
1.5060 \\
1.5182\end{array}$ & $\begin{array}{l}1.5136 \\
1.5266 \\
1.5047 \\
1.5183\end{array}$ & $\begin{array}{r}-.0009 \\
+.0001 \\
-.0013 \\
+.0001\end{array}$ & $\begin{array}{l}1.5147 \\
1.5268 \\
1.5063 \\
1.5181\end{array}$ & $\begin{array}{r}+.0002 \\
+.0003 \\
+.0003 \\
-.0001\end{array}$ & $\begin{array}{l}530 \\
580 \\
525 \\
545\end{array}$ \\
\hline $\begin{array}{l}39 . \\
40- \\
41-\end{array}$ & $\begin{array}{l}74.81 \\
75.48 \\
78.77 \\
80.59\end{array}$ & $\begin{array}{l}12.14 \\
15.26 \\
16.33 \\
16.17\end{array}$ & $\begin{array}{r}13.05 \\
9.26 \\
4.90 \\
3.24\end{array}$ & $\begin{array}{l}1.5211 \\
1.5138 \\
1.5003 \\
1.4939\end{array}$ & $\begin{array}{l}1.5222 \\
1.5138 \\
1.5010 \\
1.4955\end{array}$ & $\begin{array}{r}+.0011 \\
.0000 \\
+.0007 \\
+.0016\end{array}$ & $\begin{array}{l}1.5214 \\
1.5134 \\
1.5002 \\
1.4943\end{array}$ & $\begin{array}{r}+.0003 \\
-.0004 \\
-.0001 \\
+.0004\end{array}$ & $\begin{array}{l}590 \\
590 \\
515 \\
565\end{array}$ \\
\hline
\end{tabular}




\section{MEASUREMENT OF INDEX OF REFRACTION}

The measurement of the indices of refraction presented difficulties because many of the glasses, especially those of low silica content, were very hygroscopic. In fact, most of them were so unstable that it was impossible to grind and polish Pulfrich slabs for index measurements. Consequently a different method was used. This was essentially an immersion method, whereby the index of refraction of a glass sample was matched by that of a liquid, and the index of the liquid then measured with an Abbe refractometer.

The apparatus for measuring index of refraction by this method is illustrated diagrammatically in Figure 2.

The immersion tank was equipped with two parallel plate glass windows to permit passage of light through the liquid, and was partially inclosed by a water chamber through which tap water was continually flowing. Water from the same source was also flowing through the refractometer to keep both the immersion liquid and the

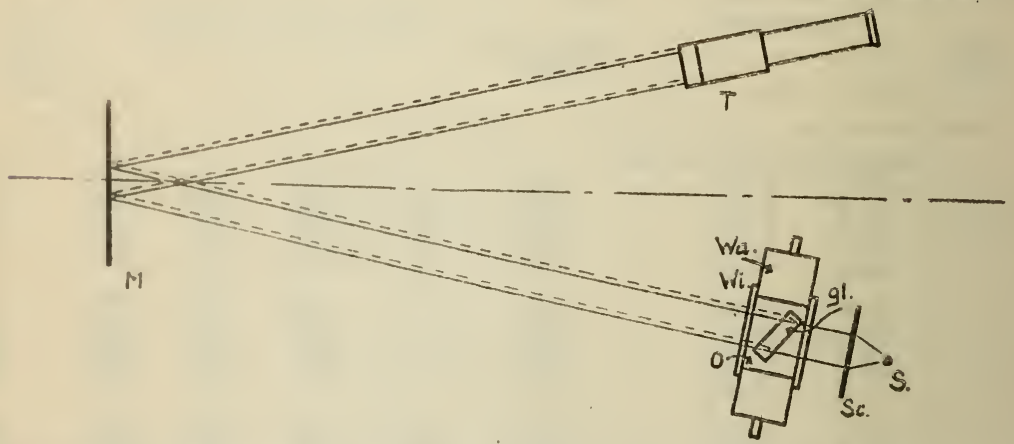

FIGURE 2.-Diagrammatic sketch of immersion tank and optical system used in determining index of refraction

The Abbe refractometer is not shown. Key: Wa, water chamber; $W i$, windows; $O$, immersion tank; $9 l$, glass sample; Sc, object screen; $S$,
source of light; $M$, tnirror; $T$, telescope.

refractometer at practically the same temperature, and thus to eliminate any significant errors that might arise from temperature differences. The thermometers in the immersion liquid and in the water jacket of the refractometer prisms never differed from each other by more than $0.25^{\circ} \mathrm{C}$.

The "object" (Sc in fig. 2) was a piece of fine-ground glass on which black cross lines were ruled. The source of light was a sodium flame. A telescope for observation, a mirror, a clip for suspension of the samples, and a stirrer to mix the component oils of the immersion liquid were also provided.

Two oils were used, Halowax oil $\left(N_{d}=1.635\right)$ and a light mineral oil $\left(N_{d}=1.463\right)$, making it possible to obtain a mixture having any
index between 1.463 and 1.635 .

In making index measurements the object screen $(S c)$ was illuminated by the sodium flame $(S)$, the light after passing through the vil $(O)$ and the sample $(g l)$, being reflected by the mirror $(M)$ to the telescope. $\left(T^{\prime}\right)$. The telescope was focused on the lines of the ubject screen. Then the oil and the glass were matched for index by 
adding, with constant stirring, small amounts of one or the other of the oils to change slowly the index of the mixture until the mixed oils matched the glass. When not matched the lines of the object screen were distorted or broken up. Also, the lines visible through the sample shifted in position as the sample was rotated. When perfectly matched no distortion or shifting of the lines was observed, regardless of the position, motion, or shape of the sample. The index of refraction of the oil was then measured with the Abbe refractometer. Of course, it was necessary to have glass samples relatively free from strix or the lines would be distorted by differences of index of refraction within the glass.

The reliability of this method was checked with several samples whose indices had previously been measured with a carefully calibrated Pulfrich refractometer. These indices were problably accurate to a few units in the fifth decimal place. The differences between the indices of refraction determined by the immersion and Pulfrich methods were less than two units in the fourth decimal place; these differences are within the limits of accuracy of the Abbe refractometer used.

\section{DATA OBTAINED AND RESULTS}

Forty-two samples of glass suitable for index determinations were made. The compositions and indices of refraction of these glasses, and also the temperatures at which they were annealed, are given in Table 1.

If the indices of refraction of the soda-silica glasses are plotted against the silica or soda content of the glasses, an approximately smooth curve will be obtained. Although a curve of this kind can be represented by a number of different equations, it was found that satisfactory values for the refractivity of these glasses could be computed by the equation:

$$
(N-1)=0.5054+0.000887 A-0.000013543 A^{2}
$$

in which $N$ is the index of refraction for sodium light, $A$ is the percentage of silica, and the constants have been adjusted by the method of least squares.

Equation (1) can be arbitrarily divided into two others, one involving silica and the other involving soda; one group of such expressions is

$$
\begin{aligned}
& \left(n_{a}-1\right)=0.005941 A-0.000013543 \Lambda^{2} \\
& \left(n_{b}-1\right)=0.005054 B
\end{aligned}
$$

in which $A$ and $B$ represent the percentages of silica and soda, respectively, and $n_{a}$ and $n_{b}$ represent their contributions to the index of refraction of the glass as computed for the silica and soda content from equations (2) and (3). Consequently, then

$$
(N-1)=\left(n_{a}-1\right)+\left(n_{b}-1\right)
$$

gives the refractivity for the 2-component system.

For convenience " $n$ " will be called a "partial index" of the glass, and when written with a subscript, such as $n_{a}$, the subscript will indicate the particular oxide in the glass to which the corresponding 
capital letter refers. Regarding the derivation of equations (2) and (3), it is obvious that the effect of soda on the index of the glasses was assumed to be a linear function and all the curvature expressed by the last term in equation (1) was attributed to the silica.

If, now, we assume that the partial substitution of lime for soda in the soda-silica glasses does not affect the silica equation. (2), then equations (2) and (3) can be used to compute the partial indices for the silica and soda in the glasses containing lime and the differences between the sum of these partial indices and the observed index of the lime glasses should yield data from which an expression for the partial index of lime can be computed. Proceeding on this assumption, the equation for the partial index of lime $(C)$ is found to be

$$
\left(n_{c}-1\right)=0.00707 C
$$

Hence, for the soda-lime-silica glasses

$$
(N-1)=\left(n_{a}-1\right)+\left(n_{b}-1\right)+\left(n_{c}-1\right)
$$

may be used for computing the refractivities.

The results obtained by equation (6) for all the glasses considered in this report are given in column A1, Table 1 . The differences between the observed and computed values are given in column A2.

A consideration of the deviations (column A2, Table 1) for glasses 1 to 21, which are listed in the order of their increasing silica content, suggests a decided tendency toward systematic variations; this might merely indicate that equation (1) is not exactly of the best type to express properly the relations between composition and index of refraction, but several other expressions (some involving fractional exponents and otiers including terms in the second power of $N$ and the cross product of $N$ and $A$ ) were tried with quite similar results. The explanation of this systematic behavior of the residuals is apparent when the soda-silica data are carefully plotted on a large scale. It then becomes evident that the index of refraction of the sodasilica glasses does not change with composition in a manner such as to form a continuous curve like the values computed by (1), but from the data presented it seems that a broken curve made up of segments of three straight lines will more accurately express the relations.

These straight lines apparently intersect at points corresponding to 59.5 and 73.75 per cent silica and these percentages correspond quite closely to the silica content of $2 \mathrm{Na}_{2} \mathrm{O} \cdot 3 \mathrm{SiO}_{2}$ and $\mathrm{Na}_{2} \mathrm{O} \cdot 3 \mathrm{SiO}_{2}$. This raises the question as to whether the changes in index with composition of the soda-silica glasses can be accurately represented by a smooth curre, as is ordinarily believed, or whether the index changes in a simpler (linear) manner which is directly related to certain molecular combinations which may be present in the glass.

Apparently this straight-line hypothesis can be applied to that part of the 3-component system discussed in this report, for the index of refraction of the soda-lime-silica glasses can also be more nccurately expressed by straight-line equations. The general equation for the soda-silica and soda-lime, silica glasses is:

$$
(N-1)=a A+b B+c C
$$


in which $A, B$, and $C$ represent the percentages of silica, soda, and lime as before, and $a, b$, and $c$ are empirical constants having the following values in the indicated silica ranges:

\begin{tabular}{|c|c|c|c|}
\hline Silica range (in per cent) & $a$ & $b$ & $c$ \\
\hline $\begin{array}{l}50 ? \text { to } 59.5 \\
59.5 \text { to } 73.75 \\
73.75 \text { to } 100\end{array}$ & $\begin{array}{r}0.004836 \\
.004785 \\
.004584\end{array}$ & $\begin{array}{r}0.005491 \\
.005568 \\
.006127\end{array}$ & $\begin{array}{r}0.007521 \\
.007598 \\
.007977\end{array}$ \\
\hline
\end{tabular}

The 50 per cent limit for silica is subject to question, i,acause the indicated constants $(a, b, c)$ for the silica range 50 to 59.5 per cent may apply to glasses containing less than 50 per cent silica. No glasses containing less than 50 per cent silica were made. The limiting silica value of 73.75 per cent applies only to the soda-silica glasses. For lime glasses it gradually changes, as the lime is increased, to approximately 71 per cent silica when the lime content reaches 16 per cent. The limiting silica value in this case is indicated by the line $b b^{\prime}$ in Figure 3.

The division lines between two adjacent groups were located by solving the corresponding equations simultaneously for the points of intersection of constant index lines. It will be observed that the boundary, $a a^{\prime}$, between the first and second groups follows a constant silica line while $b b^{\prime}$ between the second and third deviates toward lower silica values as the percentage of lime increases.

The results obtained by the proper substitutions in equation are given in columns B1 and B2 of Table 1 .

Comparing the deviations in columns A2 and B2 (Table 1), it can be seen that those in $\mathrm{B} 2$ are appreciably smaller than those in $\mathrm{A} 2$ and also that the tendency to systematic variation is less evident in B2 than in A2.

If equations (6) and (7) are used to calculate the compositions of glasses having the same index of refraction, and these compositions plotted on a triordinate graph, lines of equal index of refraction are readily located. This was done, and the resulting lines for equal index are shown in Figure 3. The "dash" lines in Figure 3 are the lines of equal index of refraction of the soda-lime-silica glasses computed from equation (6). The dotted lines are the equal-index lines determined by Morey and Merwin, ${ }^{8}$ and the solid lines are those derived from equation (7).

It becomes evident, after considering Figure 3, that there will be an infinite number of glasses containing only soda, lime, and silica that have the same index of refraction for sodium light. For example, the composition of a glass having an index of 1.51 may vary from 40 per cent $\mathrm{Na}_{2} \mathrm{O}: 60$ per cent $\mathrm{SiO}_{2}$ to approximately 11 per cent $\mathrm{Na}_{2} \mathrm{O}: 10$ per cent $\mathrm{CaO}: 79$ per cent $\mathrm{SiO}_{2}$, provided the changes in composition follow the 1.51 index line. Furthermore, the index of a glass whose composition lies at a point between two index lines may be readily computed from the distances which separate the point from the adjacent lines.

\footnotetext{
7 These systematic variations can be more readily detected by plotting the differences at their correspond. ing points on a $\mathrm{Na}_{3} \mathrm{O}-\mathrm{CaO}-\mathrm{SiO}_{2}$ diagram.

See footnote 4, p. 993.
} 


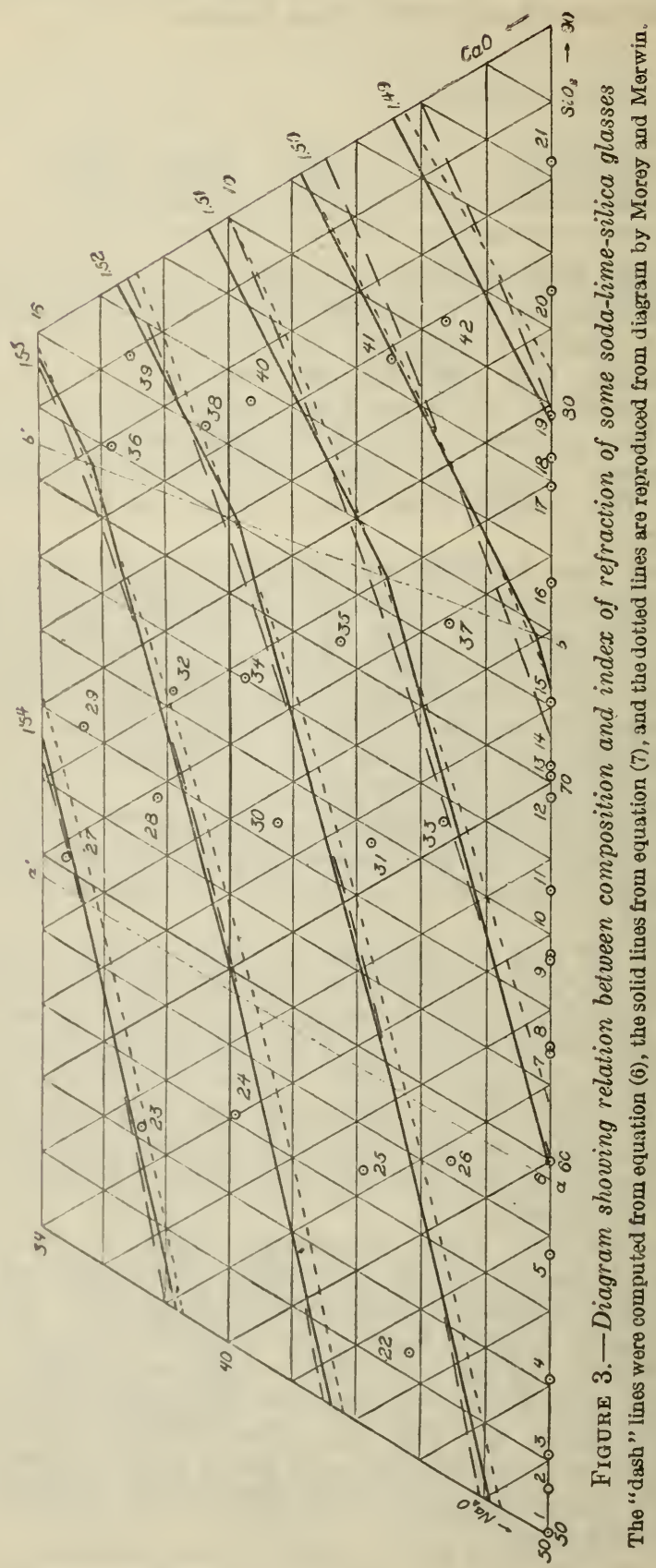


Although the equations given above can be used to compute the indices of refraction of the glasses considered, one must bear in mind the fact that the equations are wholly empirical and the division into forms involving partial indices is arbitrary.

\section{DISCUSSION}

An opinion of the reliability of the data in Table 1 and of the curves in Figure 3 can be formed only when one considers the probable accuracy of the chemical analyses and the index measurements.

The analyses of the glasses were made by F. W. Glaze, to whom credit is due for very careful and consistent work. His work was simplified by the fact that the glasses were made from very pure batch materials and were melted in platinum; consequently they did not contain more than traces of oxides other than the two or three under consideration.

Silica was determined by the ordinary fusion with sodium carbonate and double dehydration, followed by the addition of a small amount of alumina to collect residual silica with the ammonia precipitate. Appropriate blank determinations were nuade.

Soda was determined by either the J. L. Smith method, the zincuranyl acetate method, or both.

The first 15 glasses were analyzed in duplicate. The average difference between the duplicate determinations of silica was 0.07 per cent, the maximum being 0.16 per cent; the corresponding values for soda were 0.09 and 0.17 per cent.

In general, the lime glasses were not analyzed in duplicate nor were direct determinations of soda made; but for occasional checks, some determinations including soda were repeated, and the percentages of silica and soda as determined varied approximately as stated above while the average difference between the lime determinations was 0.03 per cent, the maximum being 0.09 per cent.

In all cases of complete analysis, the analyzed composition of the glass was adjusted to 100 per cent before the percentages were used in computing indices.

The reported index of refraction of the glasses is an average of three or more determinations on the same sample. Since a few strix were present in some of these glasses, it is not certain that the accuracy of \pm 0.0002 , which has been mentioned as obtainable in the method of measurement, was reached in all cases. It is thought, however, that the maximum error is not more than \pm 0.0005 .

It has been shown ${ }^{9}$ that the index of refraction (and also density) of a given glass may be materially changed by the temperature at which the glass is annealed; for instance, the index of refraction of a soda-lime glass similar to No. 39 (Table 1) will increase 0.000032 for each degree the effective annealing temperature is decreased in the range $570^{\circ}$ to $500^{\circ} \mathrm{C}$; hence, the index of No. 39 niay be made to change from 1.5211 to 1.5232 by proper heat treatment. Such changes in index (and density) are probably brought about by changes in the physicochemical constitution or equilibrium of the component constituents of the glass. Since equilibrium is attained much more quickly at higher than at lower temperatures, an effort was made to

- Tool and Hill, Trans, Soc. Glass Tech., 9, p. 196; 1925. Annual Report of Director of the Bureau of Standards, p. 25; June 30, 1929. Also, Tool, Tilton, and Hill, J. Opt. Soc. Am. and Rev. Sci. Inst., 12, p. 490; 1926. 
anneal all of the experimental glasses at high temperatures in order to reduce to a minimum the time required for annealing.

In view of the foregoing statements it is not to be expected that soda-lime-silica glasses which have known compositions and are annealed at materially lower temperatures than those used (see Table 1) will have the indices indicated by Figure 3.

Although it is recognized that the chemical analyses and the indices of refraction of the glasses considered in this paper are not of the highest possible degree of accuracy, it is thought that the relations between index of refraction and composition shown in Figure 3 are more reliable than the individual determinations on which the relations are based because all the experimental data are included and there are no serious deviations between observed and computed values.

\section{COMPARISON WITH OTHER DATA}

The results obtained by Turner ${ }^{10}$ were based on glasses containing small amounts of oxides of iron, aluminum, and magnesium. However, in the case of his data, if the amounts of iron and alumina are added to the silica, the magnesia is added to the lime, and all compositions adjusted to 100 per cent, and the resulting percentages substituted in equations (6) or (7) (or used in reading from fig. 3) the agreement between observed and computed indices is very good. In fact, the average variation between the observed indices of his 11 soda-lime-silica glasses and the values computed from their compositions by these equations is less than 0.0007 , the maximum being 0.0019 .

Peddle's results do not give satisfactory agreement when considered in the same way as Turner's; this may probably be explained by the fact that his reported compositions were computed from the batch and may vary materially from the composition of the finished glass.

\section{CONCLUSION}

The significance of the work presented in this paper is threefold. First, it is possible to predict with considerable accuracy the index of refraction from the composition of any glass of the soda-lime-silica series in the range considered; second, the compositions of the numerous glasses of this series that have the same index of refraction can be predicted; and third, this work may serve as a check on the accuracy of chemical analysis of such glasses because, if a glass is annealed at a reasonably high temperature, its composition as determined by chemical analysis should fall on the line in Figure 3 representing its index of refraction.

There is also presented some evidence which suggests that the indices of refraction of the various soda-lime-silica glasses may be directly related to certain definite compositions ( and $\mathrm{Na}_{2} 0.3 \mathrm{SiO}_{2}$ ) taken either singly or as simple mixtures, but more work must he done in order definitely to establish this point. This alditional work is now under way.

Washivgton, March 30, 1931.

$10 \mathrm{~J}$, Foc. Cilue Tech., 4, p. 111; 1920. 